\title{
Prevalence, Causes, and Factors Associated with Visual Impairment and Blindness among Registered Pensioners in Ghana
}

\author{
Benjamin D. Nuertey $\mathbb{D}^{1,2}$ Kwesi Nyan Amissah-Arthur, ${ }^{3}$ Joyce Addai, ${ }^{4}$ Victor Adongo, ${ }^{1}$ \\ Augustine D. Nuertey, ${ }^{5}$ Clement Kabutey, ${ }^{6}$ Isaac Asimadu Mensah, ${ }^{1}$ \\ and Richard Bekoe Biritwum ${ }^{2}$ \\ ${ }^{1}$ Tamale Teaching Hospital, Tamale P. O. Box TL 16, Tamale, Ghana \\ ${ }^{2}$ Community Health Department, School of Public Health, University of Ghana, Korle-Bu, Ghana \\ ${ }^{3}$ Ophthalmology Unit, Department of Surgery, Korle Bu Teaching Hospital, College of Health Sciences, \\ School of Medicine and Dentistry, University of Ghana, Accra, Ghana \\ ${ }^{4}$ Korle-Bu Teaching Hospital, Korle-Bu, Ghana \\ ${ }^{5}$ St Francis Xavier Hospital, Assin Fosu, Ghana \\ ${ }^{6}$ Nursing and Midwifery Training College, Koforidua, Ghana
}

Correspondence should be addressed to Benjamin D. Nuertey; ben.nuertey@gmail.com

Received 13 May 2019; Accepted 9 September 2019; Published 7 October 2019

Academic Editor: Takayuki Baba

Copyright (c) 2019 Benjamin D. Nuertey et al. This is an open access article distributed under the Creative Commons Attribution License, which permits unrestricted use, distribution, and reproduction in any medium, provided the original work is properly cited.

Purpose. To determine the prevalence, causes, and factors associated with presenting visual impairment and blindness among pensioners. Design. A nationwide cross-sectional study. This study was part of the analysis on data obtained in the pensioners' medical survey conducted among members of the National Pensioners Association in Ghana. Method. (i) Setting: it was a multicenter study involving thirteen centers throughout Ghana with a center in each regional capital. (ii) Study population: the study involved 4813 pensioners. (iii) Observation procedures: data were captured through the use of questionnaires, physical examinations including eye examinations, and urine and blood sample analysis. (iv) Main outcome measure: presenting visual impairment and blindness (as defined by the WHO ICD-10 classification). Results. The overall prevalence of blindness among pensioners in Ghana was 3.8\% (95\% CI $=3.2-4.4)$, while the prevalence of moderate and severe visual impairment was $21.7 \%(95 \%$ $\mathrm{CI}=20.5-23.0)$. The prevalence of blindness was lowest in the $60-65$-year-old age group $(2.1 \%(95 \% \mathrm{CI}=1.3-2.8))$ and highest in the above 80 -year-old age group $(12.2 \%(95 \% \mathrm{CI}=6.6-17.8))$. Cataract was the leading cause of blindness $(62.4 \%)$ and moderate and severe visual impairment (55.7\%). Factors significantly associated with blindness and visual impairment include educational status, vegetarianism, arthritis, and having proteins in urine. Conclusion. There is a high prevalence of visual impairment and blindness among the pensioners in Ghana. Sadly, the greatest cause was cataract, which is correctable. Increase in formal education status will be important in the prevention of blindness and visual impairment.

\section{Introduction}

Visual impairment due to any cause is a major cause of significant morbidity, and it affects many globally [1]. In the year 2010, it was estimated that 285 million people were visually impaired worldwide, of which 39 million were blind and 246 million had low vision [2]. It was estimated that, without intervention, the prevalence of blindness might reach 76 million by the year 2020 [3]. In the elderly, aged 50 years and above, the global prevalence of blindness was estimated at $1.9 \%$ with moderate and severe vision impairment (MSVI, <6/18-3/60) estimated at $10.4 \%$ with about 31 million of global 36 million blind people within this age group $[4,5]$. However, with the introduction of the global initiative to eliminate avoidable blindness (vision 2020: the right to sight), many agree that the initiative is in the right direction to reduce the prevalence of avoidable blindness $[6,7]$. In the WHO Africa region, the prevalence of blindness 
in the year 2010 was estimated as 7300 per million of which $81.7 \%$ was among those aged 50 years and above $[2,8]$. In Ghana, the World Health Organization (WHO) Study on global AGEing and adult health (SAGE) wave one which was conducted between 2007 and 2010, estimated the prevalence of low vision among adults 50 years or more to be $12.9 \%$ [9]. However, population-based studies in sections of the country among those aged 40 years and over had reported blindness prevalence ranging from $1.2 \%$ to $4.4 \%$, with one study reporting a visual impairment prevalence of $17.1 \%$ $[10,11]$. The current findings from the Ghana blindness and visual impairment study 2015 show that $19.12 \%$ of those aged 80 and above are blind [12].

There were varied underlying causes of visual impairment and blindness. It was estimated in the year 2010 that about $65 \%$ of blindness and $76 \%$ of the people with moderate/severe visual impairment worldwide were from preventable causes [13]. Recent studies reported cataract as the leading cause of blindness worldwide [14-16]. The leading cause of visual impairment, however, was uncorrected refractive error $[1,2]$. Regardless of its cause, visual impairment or blindness was associated with reduced quality of life [17].

The aim of this study was to determine the current prevalence, causes, and factors associated with visual impairment and blindness among pensioners in Ghana. This study used the current WHO ICD $10^{\text {th }}$ revision recommendation of presenting visual acuity in the best eye to classify study participants. The study reported on the prevalence, causes, and factors associated with blindness and visual impairment.

\section{Method}

2.1. Study Design. A cross-sectional study was conducted with study participants from all ten regions of Ghana. Members of the National Pensioners Association (NPA) took part in the survey. It involved questionnaire interviews and physical examinations as well as laboratory examinations of urine and blood samples collected from study participants. The survey was conducted as part of a registration exercise for all members of the National Pensioners Association for the start of a Pensions Medical Scheme (PMS) [18]. The scheme was aimed as a top-up health insurance scheme for the members of the National Pensioners Association. It is suggested that the medical scheme would finance health care expenses of members of the National Pensioners Association in instances where the health care claim is outside the coverage of the National Health Insurance Scheme (NHIS). It was a nationwide exercise that took place from April to December 2014. Members of the National Pensioners Association converged at the registration/medical screening centers within the days of the screening.

2.2. Study Sites. The study took place in thirteen sites of which ten were in the regional capitals of the ten regions of Ghana, West Africa. The study settings were mainly urban.
However, participants from nearby rural areas of each of the study sites also took part in the study. All the studies took place in thirteen sites across the country Ghana, with at least one site per the ten regions of Ghana.

2.3. Study Population and Eligibility Criteria. The study subjects were pensioners, and the majority of the pensioners were qualified as elderly as defined by the United Nations classification of 60 years and above [19]. There were some participants below 60 years who retired before the mandatory retirement age of 60 years due to disability and other reasons thereby, qualifying as pensioner. All pensioners who were members of the National Pensioners Association were eligible as participants of the study. Within the study period, 4813 members of the National Pensioners Association presented for the medical screening. The participant must be a member of the National Pensioners Association and must be a resident in Ghana.

2.4. Sample Size and Sampling Method. The aim was to screen all the members of the National Pensioners Association within and around the study sites. The estimated total number of eligible pensioners in and around the study sites was about 5000. Of these 4813 pensioners took part in the study.

2.5. Definitions and Eye Examinations. The Snellen chart in standard good illumination was used at a distance of six meters to measure the visual acuity. The tumbling "E" chart was used in instances that the pensioner had no formal education. Mild or no visual impairment was defined in this study as presenting distance visual acuity in the better eye equal to or better than $6 / 18(20 / 70,3 / 10,0.3)$, which was consistent with the WHO ICD-10 category zero. Moderate visual impairment was defined as presenting distance visual acuity in the better eye worse than $6 / 18$ but better or equal to $6 / 60(20 / 200,1 / 10,0.1)$ corresponding to category 1 of the ICD-10 H54 categorization. Severe visual impairment was defined in the study as presenting distance visual acuity in the better eye worse than 6/60 but better or equal to $3 / 60(20 / 400,1 / 20,0.05)$ corresponding to category 2 of the WHO ICD-10 H54 categorization. Moderate visual impairment and severe visual impairment were put together in the final analysis of this study and termed moderate and severe visual impairment (MSVI).

Blindness corresponding to category 3, 4, and 5 in the ICD-10 H54 categorization was put together in this study and termed blindness. Blindness was therefore defined as presenting distance visual acuity worse than 3/60. Additionally, examination of the anterior and posterior segments using a direct ophthalmoscope was performed. For other causes of visual impairment and blindness, we used the definitions from the 10th revision of International Statistical Classification of Diseases, injuries, and causes of death (ICD10).

2.6. Study Materials and Data Capture Tool. Study questionnaires recorded sociodemographic data of participants. 
The past medical history of participants was collected. As was information on allergies, alcohol consumption, smoking, exercise, and diet. There was a physical examination form attached, which was used to capture data of the physical examination conducted by medical officers. Weight was measured with a weighing scale and height with a stadiometer. Blood pressure was measured using a standardized and validated electronic sphygmomanometer with appropriate cuff sizes. Visual acuity was checked using a Snellen chart and the tumbling "E" chart. Blood sample was taken, and a glucometer was used to measure the random blood sugar. Blood sample was collected into a serum separator bottle and transported to a laboratory for measurement of serum cholesterol using automated and standardized techniques.

2.7. Data Collection. Trained research assistants filled the questionnaire based on the response of the study participants. The weight was measured to the nearest one-kilogram, while the height to the nearest one-millimeter. Random blood sugar was measured using a glucometer. Medical officers perform physical examination, while the eye team checked the vision and carried out the comprehensive eye examinations. Personalized reports of the medical screening were sent to each participant.

2.8. Data Processing and Analysis. The data generated in the research were entered into EPIDATA 3.1 and exported into STATA/MP 11.0 (copyright 2004-2009) for analysis. The primary outcome in the study was presenting visual impairment and blindness. With regard to social class, the participants' previous occupation was classified under various social class headings according to the Registrar General's occupational classification of England and Wales [20]. The background characteristics of the respondents were obtained by cross tabulation. Causes of the visual impairment and blindness were tabulated based on the findings of the comprehensive eye exam. Causes with smaller frequencies and in instances with indeterminate causes were grouped together and termed "others." Logistic regression was used to analyze the factors associated with blindness and visual impairment. First, the association between each of the potential factors and visual impairment/blindness was examined ignoring other variables. This analysis was important because it gave a fair idea as to which of the variables were strong predictors/related to visual impairment/blindness. Second, to construct a model with factors that were independently associated with visual impairment/blindness, and each of the independent variable was a candidate provided that the $P$ value was 0.05 or less. A $P$ value of 0.05 or less was considered statistically significant. With regards to the causes of moderate and severe visual impairment or blindness, multiple response analysis was carried out to rank the causes, and the results were tabulated as such.

2.9. Ethical Considerations. Review and approval was obtained from the National Pensioners Association board.
The board further monitored each step of the data collection process. The content of the medical screening exercise was developed in extensive consultation with the executives of the National Pensioners Association. The study followed the tenets of the Declaration of Helsinki. Consent was voluntary, and each study participant had the right to withdraw at any stage of the study process. Uttermost privacy and confidentiality were maintained. No compensation or payments were made to any study participants. The results of the physical examination were carefully explained to all participants and were counselled on healthy lifestyle in old age. Personalized results of the study were sent to each participant in a sealed envelope to be given to his or her physician for further explanation. Data files were password protected. Hard copy data were stored in locked file cabinets, and access was limited to the principal investigator.

\section{Results}

3.1. Background Characteristics of the Study Participants. Table 1 displays the background characteristics of the study participants. Sixty-nine percent of the study participants were males, while $31 \%$ were females. The median age of the study participants was 66 (interquartile range $=7$ ) years.

3.2. Prevalence of Presenting Blindness and Presenting Visual Impairment among Pensioners in Ghana. Table 2 displays the prevalence of moderate and severe visual impairment (MSVI) and the prevalence of blindness among study participants. The overall prevalence of blindness among pensioners in Ghana was 3.8\% (95\% CI $=3.2-4.4)$, while the prevalence of moderate to severe visual impairment was $21.7 \%$ (95\% CI $=20.5-23.0)$. Thus, overall 256 per 1000 pensioners were either blind or visually impaired. The prevalence of blindness and visual impairment was worse in males. Thus, $22.6 \%(95 \% \mathrm{CI}=21.1-24.1)$ of the males were moderately and severely visually impaired (MSVI), whereas $19.7 \%$ (95\% CI $=17.6-21.8)$ of the females were MSVI. Similarly, $4.5 \%(95 \% \mathrm{CI}=3.8-5.2)$ of the males were blind compared with $2.4 \%$ ( $95 \% \mathrm{CI}=1.5-3.2)$ among the females.

Generally, there was an increasing prevalence of blindness and moderate and severe visual impairment with increasing age. The prevalence of blindness was lowest in the below 65-year-old age group, thus $2.1 \%(95 \% \mathrm{CI}=1.3-2.8)$ and highest in the above 80-year-old group (12.2\% (95\% $\mathrm{CI}=6.6-17.8)$ ). Similarly, the prevalence of moderate and severe visual impairment $(15.2 \%(95 \% \mathrm{CI}=12.4-17.0))$ was lowest in the below 65-years age group and highest in the 80 years and above group $(39.7 \%(95 \% \mathrm{CI}=31.3-48.1))$. The prevalence of pensioners in Ghana who were either blind or MSVI was 173 per 1000 in the below 65-years age group, and it increased with increasing age to as high as 519 per 1000 in the 80 years and above group. The prevalence of blindness and MSVI generally decreases with increasing highest educational status. Pensioners who had no formal education had the highest prevalence of blindness and MSVI among the study participants. 
TABLE 1: Background characteristics of study participants.

\begin{tabular}{|c|c|c|c|}
\hline \multicolumn{4}{|c|}{ Proportion by sex } \\
\hline Participant characteristics & Female $n(\%)$ & Male $n(\%)$ & All participants $N$ (column \%) \\
\hline All participants & $1,482(31.0)$ & $3,300(69.0)$ & $4,782(100)$ \\
\hline \multicolumn{4}{|l|}{ Age in years } \\
\hline $60-65$ & $704(50.5)$ & $960(31.4)$ & $1,664(37.3)$ \\
\hline $66-69$ & $461(33.1)$ & $1,056(34.5)$ & $1,517(34.0)$ \\
\hline $70-74$ & $166(11.9)$ & $627(20.5)$ & $793(17.8)$ \\
\hline $75-79$ & $50(3.6)$ & $295(9.7)$ & $345(7.7)$ \\
\hline$\geq 80$ & $14(1.0)$ & $123(4.0)$ & $137(3.1)$ \\
\hline \multicolumn{4}{|l|}{ Current marital status } \\
\hline Never married & $36(2.6)$ & $40(1.3)$ & $76(1.7)$ \\
\hline Married & $556(40.3)$ & $2,679(88.0)$ & $3,235(73.1)$ \\
\hline Widow/widower & $511(37.1)$ & $200(6.6)$ & $711(16.1)$ \\
\hline Divorced & $157(11.4)$ & $63(2.1)$ & $220(5.0)$ \\
\hline Separated & $119(8.6)$ & $62(2.0)$ & $181(4.1)$ \\
\hline \multicolumn{4}{|c|}{$\begin{array}{l}\text { Body mass index (by WHO BMI } \\
\text { cutoff/classification) }\end{array}$} \\
\hline Underweight & $34(2.4)$ & $232(7.6)$ & $266(6.0)$ \\
\hline Normal & $393(28.0)$ & $1,743(56.8)$ & $2,136(47.8)$ \\
\hline Overweight & $492(35.1)$ & $848(27.6)$ & $1,340(30.0)$ \\
\hline Obese & $483(34.5)$ & $246(8.0)$ & $729(16.3)$ \\
\hline \multicolumn{4}{|c|}{ Highest formal educational status } \\
\hline None & $70(5.4)$ & $423(15.1)$ & $493(12.0)$ \\
\hline Primary & $517(39.7)$ & $1,116(39.9)$ & $1,633(39.4)$ \\
\hline Secondary & $195(15.0)$ & $434(15.5)$ & $629(15.4)$ \\
\hline Tertiary & $452(34.7)$ & $724(25.9)$ & $1,176(28.7)$ \\
\hline Vocational & $68(5.2)$ & $100(3.6)$ & $168(4.1)$ \\
\hline \multicolumn{4}{|l|}{ Known diabetic status } \\
\hline Not a diabetic & $1,167(86.0)$ & $2,745(91.4)$ & $3,910(89.7)$ \\
\hline Known diabetic & $190(14.0)$ & $258(8.6)$ & $448(10.3)$ \\
\hline \multicolumn{4}{|l|}{ Known hypertension status } \\
\hline Not a hypertensive & $531(38.3)$ & $1,785(58.6)$ & $2,316(52.2)$ \\
\hline Known hypertensive & $857(61.7)$ & $1,262(41.4)$ & $2,119(47.8)$ \\
\hline
\end{tabular}

The prevalence of MSVI and blindness among pensioners without any formal education was 31.7\% (95\% $\mathrm{CI}=27.5-35.9)$ and $7.5 \%(95 \% \mathrm{CI}=5.1-9.9)$, respectively. The prevalence of MSVI and blindness among pensioners with tertiary education as highest educational status was $16.5 \%(95 \% \mathrm{CI}=14.3-18.7)$ and $2.8 \%(95 \% \mathrm{CI}=1.9-3.8)$, respectively.

Table 3 displays the age and sex specific prevalence of blindness and MSVI among the study participants. The prevalence of blindness in the males was higher than that among the female pensioners across the various age groups. The prevalence of blindness among male pensioners aged less than 65 years was $2.8(95 \% \mathrm{CI}=1.7-3.9)$, whereas the prevalence among female pensioners for the same age group was $1.1(95 \% \mathrm{CI}=0.3-1.8)$.

3.3. Causes of Presenting Moderate and Severe Visual Impairment (MSVI). Table 4 displays the results of a multiple response analysis of the causes of moderate to severe visual impairment. The leading cause of MSVI was cataract. It accounted for about $55.7 \%$ of all the causes of MSVI. This was followed by refractive error accounting for $22.9 \%$. Glaucoma was ranked the third highest cause of presenting MSVI among the pensioners accounting for $8.6 \%$ of all the causes of MSVI. Cataract surgery was fairly common. The other causes of MSVI were retinal diseases (4.1\%), age-related macular degeneration (3.1\%), cornea opacities (1.5\%), optic nerve-related causes (1.1\%), and other causes accounting for $3.0 \%$.

3.4. Causes of Presenting Blindness among Pensioners in Ghana. Table 4 displays the causes of blindness among pensioners in Ghana. Uncorrected cataract accounted for more than half of all the causes of blindness among the pensioners. $62.4 \%$ of the presenting blindness was attributable to cataract. The second most common cause of blindness among pensioners in Ghana was glaucoma accounting for $12.9 \%$. Retinal diseases followed with $4.8 \%$. Age-related macular degeneration (3.2\%), cornea opacities (2.7\%), phthisis bulbi (2.7\%), optic nerve related (2.2\%), and others accounting for $9.1 \%$.

3.5. Combined Causes of Presenting Visual Impairment and Blindness among Pensioners in Ghana. The leading cause of visual impairment classified as MSVI and blindness put together was cataract accounting for $52.3 \%$. Refractive error (19.4\%) and glaucoma (9.2\%) also formed part of the top three causes of combined MSVI and blindness among the pensioners in Ghana. The other causes of the combined MSVI and blindness included retinal diseases (4.2\%), cornea 
TABLe 2: Prevalence of presenting blindness and visual impairment among pensioners in Ghana.

\begin{tabular}{|c|c|c|c|c|c|c|}
\hline & \multicolumn{2}{|c|}{ Mild or no visual impairment } & \multicolumn{2}{|c|}{$\begin{array}{l}\text { Moderate to severe visual } \\
\text { impairment }\end{array}$} & \multicolumn{2}{|c|}{ Blindness } \\
\hline & $n(\%)$ & $95 \% \mathrm{CI}$ & $n(\%)$ & $95 \% \mathrm{CI}$ & $n(\%)$ & $95 \% \mathrm{CI}$ \\
\hline Overall & $3,300(74.4)$ & $73.1-75.7$ & $964(21.7)$ & $20.5-23.0$ & $170(3.8)$ & $3.2-4.4$ \\
\hline \multicolumn{7}{|l|}{ Sex } \\
\hline Male & $2,236(72.9)$ & $71.3-74.5$ & $693(22.6)$ & $21.1-24.1$ & $138(4.5)$ & $3.8-5.2$ \\
\hline Female & $1,062(80.0)$ & $75.8-80.2$ & $268(19.7)$ & $17.6-21.8$ & $32(2.4)$ & $1.5-3.2$ \\
\hline \multicolumn{7}{|l|}{ Age (years) } \\
\hline$<65$ & $1,323(82.7)$ & $80.1-84.6$ & $243(15.2)$ & $12.4-17.0$ & $33(2.1)$ & $1.3-2.8$ \\
\hline $65-69$ & $1,153(78.2)$ & $76.1-80.3$ & $283(19.2)$ & $17.2-21.2$ & $39(2.64)$ & $1.8-3.4$ \\
\hline $70-74$ & $507(66.1)$ & $62.7-69.5$ & $218(28.4)$ & $25.2-31.6$ & $42(2.5)$ & $3.9-7.1$ \\
\hline $75-79$ & $182(54.8)$ & $49.5-60.2$ & $118(35.5)$ & $30.4-40.7$ & $32(9.6)$ & $6.5-12.8$ \\
\hline$\geq 80$ & $63(48.1)$ & $39.5-56.7$ & $52(39.7)$ & $31.3-48.1$ & $16(12.2)$ & $6.6-17.8$ \\
\hline \multicolumn{7}{|l|}{$\begin{array}{l}\text { Highest formal } \\
\text { educational status }\end{array}$} \\
\hline None & $291(60.8)$ & $56.3-65.1$ & $152(31.7)$ & $27.5-35.9$ & $36(7.5)$ & $5.1-9.9$ \\
\hline Primary & $1,180(74.8)$ & $72.7-80.0$ & $342(21.7)$ & $19.7-23.7$ & $55(3.5)$ & $2.6-4.4$ \\
\hline Secondary & $466(76.5)$ & $73.1-79.9$ & $123(20.2)$ & $17.0-23.4$ & $20(3.3)$ & $1.9-4.7$ \\
\hline Tertiary & $915(80.7)$ & $78.4-83.0$ & $187(16.5)$ & $14.3-18.7$ & $32(2.8)$ & $1.9-3.8$ \\
\hline Vocational & $129(80.6)$ & $74.5-86.8$ & $29(18.1)$ & $12.1-24.1$ & $2(1.3)$ & $0.5-3.0$ \\
\hline \multicolumn{7}{|c|}{$\begin{array}{l}\text { Body mass index WHO } \\
\text { classification }\end{array}$} \\
\hline Underweight & $152(60.6)$ & $54.5-44.4$ & $86(34.3)$ & $28.4-40.2$ & $13(5.2)$ & $2.4-7.9$ \\
\hline Normal & $1,493(71.7)$ & $69.7-73.6$ & $491(23.6)$ & $21.8-25.4$ & $99(4.7)$ & $3.8-5.7$ \\
\hline Overweight & $1,023(78.7)$ & $76.5-80.9$ & $243(18.7)$ & $16.6-20.8$ & $34(2.6)$ & $1.7-3.5$ \\
\hline Obese & $558(79.8)$ & $76.9-82.8$ & $122(17.5)$ & $14.6-20.3$ & $19(2.7)$ & $1.5-3.9$ \\
\hline \multicolumn{7}{|c|}{ Current smoking status } \\
\hline Nonsmoker & $3,008(80.0)$ & $73.6-76.3$ & $853(21.3)$ & $20.0-22.5$ & $151(3.8)$ & $3.2-4.4$ \\
\hline Smoker & $66(69.6)$ & $60.2-78.8$ & $23(24.2)$ & $15.5-32.9$ & $6(6.3)$ & $1.4-11.2$ \\
\hline \multicolumn{7}{|c|}{ Known diabetic status } \\
\hline Nondiabetic & $2,826(74.8)$ & $73.4-76.2$ & $808(21.4)$ & $20.1-22.7$ & $144(3.8)$ & $3.2-4.4$ \\
\hline Diabetic & $330(76.4)$ & $72.3-80.4$ & $83(19.2)$ & $15.5-22.9$ & $19(4.4)$ & $2.5-6.3$ \\
\hline \multicolumn{7}{|c|}{ Region of residence } \\
\hline Central & $97(58.1)$ & $50.6-65.6$ & $55(32.9)$ & $25.8-40.0$ & $15(9.0)$ & $4.6-13.3$ \\
\hline Upper West & $218(66.9)$ & $61.8-72.0$ & $82(25.2)$ & $20.4-29.9$ & $26(8.0)$ & $5.0-10.9$ \\
\hline Ashanti & $937(85.1)$ & $83.0-87.2$ & $123(11.2)$ & $9.3-13.0$ & $41(3.7)$ & $2.6-4.8$ \\
\hline Northern & $218(66.7)$ & $61.5-71.8$ & $87(26.6)$ & $21.8-31.4$ & $22(6.7)$ & $4.0-9.4$ \\
\hline Upper East & $156(59.1)$ & $53.1-65.0$ & $96(36.4)$ & $30.5-42.2$ & $12(4.6)$ & $2.0-7.1$ \\
\hline Brong-Ahafo & $210(75.8)$ & $70.8-80.9$ & $55(19.9)$ & $15.1-24.6$ & $12(4.3)$ & $1.9-6.7$ \\
\hline Western & $415(64.6)$ & $60.9-68.3$ & $208(32.4)$ & $28.7-36.0$ & $19(3.0)$ & $1.6-4.3$ \\
\hline Volta & $346(71.8)$ & $67.8-75.8$ & $126(26.1)$ & $22.2-30.1$ & $10(2.1)$ & $0.8-3.3$ \\
\hline Eastern & $345(87.6)$ & $84.2-90.8$ & $41(10.4)$ & $7.4-13.4$ & $8(2.0)$ & $0.6-3.4$ \\
\hline Greater Accra & $313(82.6)$ & $78.8-86.4$ & $62(16.4)$ & $12.6-20.0$ & $4(1.1)$ & $0.03-2.0$ \\
\hline
\end{tabular}

TABLe 3: Age and sex specific prevalence of blindness and visual impairment among pensioners in Ghana.

\begin{tabular}{|c|c|c|c|c|c|c|}
\hline \multirow[t]{2}{*}{ Sex stratified by age } & \multicolumn{2}{|c|}{ Mild or no visual impairment } & \multicolumn{2}{|c|}{$\begin{array}{c}\text { Moderate to severe visual } \\
\text { impairment }\end{array}$} & \multicolumn{2}{|c|}{ Blindness } \\
\hline & $n(\%)$ & $95 \% \mathrm{CI}$ & $n(\%)$ & $95 \% \mathrm{CI}$ & $n(\%)$ & $95 \% \mathrm{CI}$ \\
\hline \multicolumn{7}{|c|}{$\begin{array}{l}\text { Males stratified by age } \\
\text { in years }\end{array}$} \\
\hline$<65$ & $758(81.5)$ & $79.0-84.0$ & $146(15.7)$ & $13.4-18.0$ & $26(2.8)$ & $1.7-3.9$ \\
\hline $65-69$ & $807(78.6)$ & $76.0-81.1$ & $191(18.6)$ & $16.2-21.0$ & $29(2.8)$ & $1.8-3.8$ \\
\hline $70-74$ & $407(66.3)$ & $62.5-70.0$ & $174(28.3)$ & $24.8-31.9$ & $33(5.4)$ & $3.6-7.2$ \\
\hline $75-79$ & $156(54.7)$ & $48.9-60.5$ & $99(34.7)$ & $29.2-40.3$ & $30(10.5)$ & $7.0-14.1$ \\
\hline$\geq 80$ & $59(50.0)$ & $40.9-59.1$ & $46(40.0)$ & $30.1-47.8$ & $13(11.0)$ & $5.3-16.7$ \\
\hline \multicolumn{7}{|c|}{$\begin{array}{l}\text { Females stratified by age } \\
\text { in years }\end{array}$} \\
\hline$<65$ & $565(84.5)$ & $81.7-87.2$ & $97(14.5)$ & $11.8-17.2$ & $7(1.1)$ & $0.3-1.8$ \\
\hline $65-69$ & $345(77.4)$ & $73.4-81.2$ & $91(20.4)$ & $16.7-24.2$ & $10(2.2)$ & $0.9-3.6$ \\
\hline $70-74$ & $100(65.4)$ & $57.8-72.9$ & $44(28.8)$ & $21.6-36.0$ & $9(5.9)$ & $2.1-9.6$ \\
\hline $75-79$ & $26(55.3)$ & $40.9-69.7$ & $19(40.4)$ & $26.2-54.6$ & $2(4.3)$ & $1.6-10.1$ \\
\hline$\geq 80$ & $4(30.7)$ & $4.6-56.9$ & $6(46.2)$ & $17.9-74.4$ & $3(23.1)$ & $0.7-46.9$ \\
\hline
\end{tabular}


TABLE 4: Causes of presenting moderate and severe visual impairment (MSVI) and presenting blindness among pensioners in Ghana.

\begin{tabular}{|c|c|c|c|c|}
\hline \multirow{2}{*}{ Rank } & \multicolumn{2}{|c|}{ Visual impairment among pensioners } & \multicolumn{2}{|c|}{ Presenting blindness } \\
\hline & Causes & $N(\%)$ & Causes & $N(\%)$ \\
\hline 1 & Cataract & $579(55.7)$ & Cataract & $116(62.4)$ \\
\hline 2 & Refractive errors & $238(22.9)$ & Glaucoma & $24(12.9)$ \\
\hline 3 & Glaucoma & $89(8.6)$ & Retinal disease & $9(4.8)$ \\
\hline 4 & Retinal disease & $43(4.1)$ & Age-related macular degeneration & $6(3.2)$ \\
\hline 5 & Age-related macular degeneration & $32(3.1)$ & Cornea opacities & $5(2.7)$ \\
\hline 6 & Cornea opacities & $16(1.5)$ & Phthisis bulbi & $5(2.7)$ \\
\hline 7 & Optic nerve related & $11(1.1)$ & Optic nerve related & $4(2.2)$ \\
\hline 8 & Others & $31(3.0)$ & Others & $17(9.1)$ \\
\hline
\end{tabular}

opacities $(1.7 \%)$, optic nerve related $(1.2 \%)$, phthisis bulbi $(0.4 \%)$, and other causes accounting for $3.9 \%$.

Factors associated with blindness and moderate and severe visual impairment among pensioners in Ghana.

In the unadjusted analysis, the odds of blindness and moderate and severe visual impairment among the males were $1.3(95 \% \mathrm{CI}=1.1-1.5)$ times that among the females as shown in Table 5. Blindness and moderate and severe visual impairment (BMSVI) increased with increasing age such that the odds of BMSVI in pensioners aged 80 years and above were about $5.2(95 \% \mathrm{CI}=3.5-7.5)$ times the odds of BMSVI among the pensioners below 65 years. Also, increasing highest educational status was associated with reduced risk of BMSVI. The odds of BMSVI among pensioners with no formal education were $2.7(95 \% \mathrm{CI}=1.7-4.1)$ times the odds of BMSVI among the pensioners with the highest educational status as tertiary or vocational/technical training.

Body mass index was associated with BMSVI. Compared with the pensioners with normal BMI, being obese was associated with lower risk of presenting BMSVI (0.6, 95\% $\mathrm{CI}=0.5-0.9)$, whereas underweight was associated with an increased risk $(1.7,95 \% \mathrm{CI}=1.3-2.2)$ of being blind and moderately or severely visually impaired. Vegetarians were $1.8(95 \% \mathrm{CI}=1.2-2.8)$ times likely to be blind and moderately or severely visually impaired compared to nonvegetarians. Social class was another factor associated with BMSVI. The social class V made up of unskilled according to the Registrar General social class classification was most associated with BMSVI $(1.9,95 \% \mathrm{CI}=1.3-3.6)$ compared to the professional group. Other factors like arthritis was marginally associated with BMSVI $(1.2,95 \% \mathrm{CI}=1.0-1.4)$. Raised serum lipids were associated with lower odds of BMSVI among the pensioners. Raised triglyceride $(0.7,95 \%$ $\mathrm{CI}=0.5-1.0)$, low-density lipoprotein $(0.8,95 \% \mathrm{CI}=0.6-$ $0.9)$, and total cholesterol $(0.8,95 \% \mathrm{CI}=0.6-0.9)$ were associated with reduced odds of BMSVI compared to having normal levels of triglyceride, low-density lipoprotein, and total cholesterol, respectively.

Having proteins in the urine was associated with BMSVI. Positive urine protein was associated with 1.5 (95\% $\mathrm{CI}=1.2-1.9)$ times the odds of BMSVI compared with the odds of having normal urine protein. Table 5 displays the findings from the logistic regression.

3.6. Adjusted Analysis. The adjusted odds ratios are displayed in Table 6. Model A adjusted for age and sex, while model B adjusted for age, sex, and highest educational status. Formal education was protective against BMSVI in the adjusted analysis compared with no formal education. Primary education was associated with $30 \%$ reduced risk of BMSVI $(0.7,95 \% \mathrm{CI}=0.5-0.9)$. Similarly, secondary education as the highest formal educational status was also associated with a reduced risk of BMSVI $(0.7,95 \% \mathrm{CI}=0.5-0.9)$.

Tertiary education and vocational/technical education as highest formal education was associated with reduced risk of BMSVI $(0.6,95 \% \mathrm{CI}=0.4-0.7)$ and $(0.5,95 \% \mathrm{CI}=0.3-0.8)$, respectively. Also, in the adjusted analysis, the odds of BMSVI were high in the underweight WHO BMI classification group $(1.5,95 \% \mathrm{CI}=1.1-1.9)$, whereas it was reduced in the WHO overweight group $(0.8,95 \% \mathrm{CI}=1.0-0.9)$. Vegetarians were $1.9(95 \% \mathrm{CI}=1.2-3.0)$ times more associated with BMSVI compared to nonvegetarians. Pensioners having a history of arthritis were associated with BMSVI in the adjusted analysis $(\mathrm{AOR}=1.2,95 \% \mathrm{CI}=0.5-1.5)$ compared to pensioners with no such history. Urine proteins were associated with BMSVI. Pensioners with trace urine proteins were $1.3(95 \% \mathrm{CI}=1.1-1.9)$ times more likely to be blind and moderately or severely visually impaired compared with those with normal urine proteins. Also pensioners with urine proteins greater than $30 \mathrm{mg} / \mathrm{dl}$ or $0.3 \mathrm{mmol} / \mathrm{L}$ were $1.5(95 \% \mathrm{CI}=0.5-1.0)$ times more likely to have BMSVI.

\section{Discussion}

Age has been a significant factor that influenced the development of visual impairment and blindness. Age has been described as an important related factor in eye disease [21]. More than half (519 per 1000) of all pensioners above the age of 80 in Ghana have a visual impairment with 122 per 1000 pensioners 80 years and above blind. The above statistics is worrisome since majority of causes of blindness and visual impairment in Ghana were from preventable causes. According to findings from the Ghana blindness and visual impairment study 2015, more than half of blindness in Ghana was caused by cataract [12].

The prevalence of blindness and MSVI generally decreased with increasing highest educational status. Pensioners who had no formal education had the highest prevalence of blindness and MSVI among the study participants. Education and occupation have been used as proxy for socioeconomic status [22] which has been linked with visual impairment $[23,24]$. It has been shown that people 
TABLe 5: Factors associated with blindness and moderate and severe visual impairment among pensioners in Ghana.

\begin{tabular}{|c|c|c|c|}
\hline & Crude odds ratio & 95\% confidence interval & $P$ value \\
\hline \multicolumn{4}{|l|}{ Sex } \\
\hline Male & 1.3 & $1.1-1.5$ & $<0.0005$ \\
\hline Female & - & - & \\
\hline \multicolumn{4}{|l|}{ Age in years } \\
\hline$<65$ & - & - & \\
\hline $65-69$ & 1.3 & $1.1-1.6$ & $<0.0001$ \\
\hline $70-74$ & 2.5 & $2.0-3.0$ & \\
\hline $75-79$ & 4.0 & $3.1-5.1$ & \\
\hline$\geq 80$ & 5.2 & $3.5-7.5$ & \\
\hline \multicolumn{4}{|l|}{ Highest formal education } \\
\hline No formal education & 2.7 & $1.7-4.1$ & $<0.0001$ \\
\hline Primary & 1.4 & $0.9-2.1$ & \\
\hline Secondary & 1.3 & $0.8-2.0$ & \\
\hline Tertiary & 1.0 & $0.7-1.5$ & \\
\hline Vocational & - & - & \\
\hline \multicolumn{4}{|c|}{ Body mass index WHO classification } \\
\hline Underweight & 1.7 & $1.3-2.2$ & $<0.0001$ \\
\hline Normal & - & - & \\
\hline Overweight & 0.7 & $0.6-0.8$ & \\
\hline Obese & 0.6 & $0.5-0.9$ & \\
\hline \multicolumn{4}{|l|}{ Vegetarian } \\
\hline \multicolumn{4}{|l|}{ Nonvegetarian } \\
\hline Vegetarian & 1.8 & $1.2-2.8$ & $<0.001$ \\
\hline \multicolumn{4}{|l|}{ History of arthritis } \\
\hline \multicolumn{4}{|l|}{ No arthritis } \\
\hline Had arthritis & 1.2 & $1.0-1.4$ & $<0.05$ \\
\hline \multicolumn{4}{|l|}{ Social class by previous occupation } \\
\hline I (professional) & - & - & $<0.0001$ \\
\hline II (managerial/technical) & 1.1 & $0.8-1.5$ & \\
\hline III (N; skilled nonmanual) & 1.0 & $0.7-1.3$ & \\
\hline III (M; skilled manual) & 1.3 & $0.9-1.8$ & \\
\hline IV (partly skilled) & 1.6 & $1.4-2.1$ & \\
\hline $\mathrm{V}$ (unskilled) & 1.9 & $1.3-2.6$ & \\
\hline \multicolumn{4}{|l|}{ Serum triglyceride level } \\
\hline \multicolumn{4}{|l|}{ Normal } \\
\hline Raised & 0.7 & $0.5-1.0$ & $<0.05$ \\
\hline \multicolumn{4}{|l|}{ Serum Ldl level } \\
\hline \multicolumn{4}{|l|}{ Normal } \\
\hline Raised & 0.8 & $0.6-09$ & $<0.05$ \\
\hline \multicolumn{4}{|l|}{ Serum total cholesterol level } \\
\hline \multicolumn{4}{|l|}{ Normal } \\
\hline Raised & 0.8 & $0.6-0.9$ & $<0.05$ \\
\hline \multicolumn{4}{|l|}{ Urine proteins } \\
\hline Negative & - & - & $<0.0005$ \\
\hline Trace & 1.3 & $1.1-1.7$ & \\
\hline Positive $(+,++,+++,++++)$ & 1.5 & $1.2-1.9$ & \\
\hline
\end{tabular}

from high social classes have a stronger health care-seeking behavior [25]. The economic empowerment of pensioners with higher educational status means that they may be more likely to seek and undertake early treatment for eye conditions. In such circumstances, they were less likely to have presented at the study with MSVI and blindness due to prior intervention.

More than half of all blindness and visual impairment in this study can be directly linked to cataract. Cataract is the leading cause of blindness worldwide, and it is a multifactorial disease associated with several factors [26]. Cataract still remains a public health problem because of lack of skilled personnel and facilities to adequately handle cases of cataract that keeps rising due to population growth [21]. It has been estimated that close to $90 \%$ of all cases of cataract globally is from developing countries; however, most of the research into cataract are in the United States and the European countries [21].

Cataract is ranked as the leading cause of blindness and visual impairment [14], a situation that was also observed in Ghana. Glaucoma was ranked the second leading cause of blindness among the pensioners in Ghana and the third leading cause of MSVI among the pensioners. Increasing age was strongly associated with the risk of being blind and moderately or severely visually impaired. Age above 80 years was associated with about five times the odds of being 
TABLE 6: Factors associated with blindness and moderate and severe visual impairment among pensioners in Ghana adjusting for age and sex in model (A) and adjusting for age, sex, and highest educational status in model B.

\begin{tabular}{|c|c|c|c|c|c|c|}
\hline & \multicolumn{3}{|c|}{${ }^{*}$ Model A } & \multicolumn{3}{|c|}{ \#Model B } \\
\hline & $\mathrm{AOR} \wedge$ & $95 \% \mathrm{CI}^{+}$ & $P$ value & $\mathrm{AOR} \wedge$ & $95 \% \mathrm{CI}^{+}$ & $P$ value \\
\hline \multicolumn{7}{|l|}{ Highest formal education } \\
\hline No formal education & - & & & & & \\
\hline Primary & 0.7 & $0.5-0.9$ & $<0.001$ & & & \\
\hline Secondary & 0.7 & $0.5-0.9$ & $<0.005$ & & & \\
\hline Tertiary & 0.6 & $0.4-0.7$ & $<0.001$ & & & \\
\hline Vocational & 0.5 & $0.3-0.8$ & $<0.005$ & & & \\
\hline \multicolumn{7}{|c|}{ Body mass index WHO classification } \\
\hline Underweight & 1.5 & $1.1-1.9$ & $<0.05$ & 1.5 & $1.1-2.1$ & 0.006 \\
\hline Normal & - & & & - & & \\
\hline Overweight & 0.8 & $0.6-0.9$ & $<0.005$ & 0.8 & $0.7-1.0$ & 0.06 \\
\hline Obese & 0.8 & $0.6-1.0$ & $<0.05$ & 0.8 & $0.6-1.0$ & 0.9 \\
\hline \multicolumn{7}{|l|}{ Vegetarian } \\
\hline Nonvegetarian & - & & & - & & \\
\hline Vegetarian & 1.9 & $1.2-3.0$ & $<0.005$ & 1.9 & $1.2-3.0$ & 0.009 \\
\hline \multicolumn{7}{|l|}{ History of arthritis } \\
\hline No arthritis & - & - & & & & \\
\hline Had arthritis & 1.2 & $1.0-1.5$ & $<0.05$ & 1.3 & $1.1-1.6$ & 0.008 \\
\hline \multicolumn{7}{|l|}{ Urine proteins } \\
\hline Negative & - & - & & - & & \\
\hline Trace & 1.3 & $1.1-1.7$ & $<0.5$ & 1.5 & $1.2-1.9$ & 0.002 \\
\hline Positive $(+,++,+++,++++)$ & 1.5 & $1.2-1.9$ & $<0.005$ & 1.5 & $1.1-1.9$ & 0.003 \\
\hline
\end{tabular}

* Model A: adjusting for age and sex. \#Model B: adjusting for age, sex, and highest educational status. AOR: adjusted odds ratio. $95 \% \mathrm{CI}^{+}$: $95 \%$ confidence interval.

BMSVI compared to that of the pensioners below 65 years. Several years of study on aging and vision have demonstrated the effects of aging and vision, which is true for almost all people from all nations including Ghana [27]. Globally, causes of blindness included age-related macular degeneration, glaucoma, corneal opacities, uncorrected refractive errors, and diabetic retinopathy [13]. In Ghana, the leading causes of blindness are from correctable causes such as cataract [12]. Causes of visual impairment included cataract, diabetic retinopathy, and age-related macular degeneration.

Nutritional factors were significantly associated with BMS visual impairment. Firstly, body mass index was found to be related with blindness and moderate and severe visual impairment. Those within the WHO BMI underweight category were about $50 \%$ more likely to be blind and moderately and severely (BMS) visually impaired. Also, analyzing the crude odds ratio, raised total cholesterol, raised low-density lipoprotein, and raised triglyceride levels were negatively associated with being BMS visually impaired. Finally, vegetarians were about twice likely to be BMS visually impaired compared to nonvegetarians. We can attribute nutritional causes to play a significant role in the development of visual impairment in the elderly.

Pensioners who were diagnosed as having any form of arthritis were more likely to be BMS visually impaired, and this may be due to the use of steroids for treating rheumatoid arthritis [28].

Also, obesity was found to confer less risk against the development of BMS visual impairment. We also noted that having proteins in the urine was associated with presenting BMS visual impairment in the elderly. This requires further studies to ascertain the nature of the proteinuria if it is of infective or renal pathology.

This study was done in pensioners; given the demographic of workers in Ghana, particularly those who have retired, there are more males in employment and subsequently more males in the pensioner category. This could also explain the higher prevalence of visual impairment in men than women, contrary to previous meta-analysis of various worldwide studies that revealed higher proportion of worldwide blindness in women than in men.

Limitations encountered in this study were that not all pensioners were members of the National Pensioners Association. Also, a significant proportion of pensioners whose previous work was in the informal sector were not members of the National Pensioners Association and such, the prevalence of blindness and visual impairment may be underestimated by this study. The setting of the study was mainly urban. Also, majority of the elderly people who had no formal education were not members of the National Pensioners Association [29] and as such, the prevalence of blindness obtained as $3.8 \%$ and the prevalence of visual impairment, which was estimated as $21.7 \%$, may be lower than what really persist among the elderly population in Ghana. This is because pensioners without any formal education were more likely to be MSVI or blind compared with any category of elderly who had some formal education [30].

The authors recommend that the Eye Care Secretariat of the Ghana Health Service should include a strategy for identifying pensioners with visual impairment and prioritize their care. There will have to be a deliberate plan to seek out these individuals using the social security system to identify them. Given the relatively young population of the country, 
there will also have to be a strategy to forecast the increase in pensioner numbers over the next few decades as well as make provision for their eye care needs. Also, the role of the National Health Insurance Scheme (NHIS) and access to preventive eye care services in Ghana need a critical review because no one should theoretically be cataract blind.

This study shows that even though there is provision for cataract surgery under the National Health Insurance Scheme of Ghana, there is a high prevalence of visual impairment and blindness due to cataract, which appears to be worse in men of lower educational status.

\section{Data Availability}

The data used to support the findings of this study are available from the corresponding author upon request.

\section{Conflicts of Interest}

The authors declare that they have no conflicts of interest.

\section{Authors' Contributions}

BDN, KNAA, JA, VA, ADN, CK, IAM, and RBK designed the study; BDN analyzed the data; BDN and KNAA drafted the manuscript; and all authors read the manuscript, made significant contribution, and approved the final manuscript.

\section{Acknowledgments}

The authors acknowledge the support of the members of the National Pensioners Association for their contribution in making this a success.

\section{References}

[1] J. Keeffe and S. Resnikoff, "Prevalence and causes of vision impairment and blindness: the global burden of disease," in Essentials in Ophthalmology [Internet], R. Khanna, G. Rao, and S. Marmamula, Eds., Springer, Cham, Switzerland, pp. 7-20, 2019.

[2] D. Pascolini and S. P. Mariotti, "Global estimates of visual impairment: 2010," British Journal of Ophthalmology, vol. 96, no. 5, pp. 614-618, 2012.

[3] L. Pizzarello, A. Abiose, and T. Ffytche, "Vision 2020: the right to sight: a global initiative to eliminate avoidable blindness," Archives of Ophthalmology, vol. 122, no. 4, pp. 615-620, 2004.

[4] M. Zetterberg, "Age-related eye disease and gender," Maturitas, vol. 83, pp. 19-26, 2016.

[5] R. R. A. Bourne, S. R. Flaxman, T. Braithwaite et al., "Magnitude, temporal trends, and projections of the global prevalence of blindness and distance and near vision impairment: a systematic review and meta-analysis," The Lancet Global Health, vol. 5, no. 9, pp. e888-e897, 2017.

[6] A. Foster and S. Resnikoff, "The impact of vision 2020 on global blindness,” Eye, vol. 19, no. 10, pp. 1133-1135, 2005.

[7] N. Muhammad and M. Adamu, "Making a difference with vision 2020: the right to sight? Lessons from two states of North Western Nigeria," Nigerian Journal of Clinical Practice, vol. 17, no. 6, 2014.

[8] K. Naidoo, S. Gichuhi, M.-G. Basáñez et al., "Prevalence and Causes of Vision Loss in Sub-saharan Africa: 1990-2010,"
British Journal of Ophthalmology, vol. 98, no. 5, pp. 612-618, 2014.

[9] R. Biritwum, G. Mensah, A. Yawson, and N. Minicuci, "Study on global AGEing and adult health (SAGE)," Wave 1: the Ghana National Report, World Health Organization, Geneva, Switzerland, 2013.

[10] J. Guzek, F. Anyomi, S. Fiadoyor, and F. Nyonator, "Prevalence of blindness in people over 40 years in the volta region of Ghana," Ghana Medical Journal, vol. 39, no. 2, pp. 55-62, 2006.

[11] D. Budenz, J. Bandi, K. Barton, W. Nolan, and L. Herndon, "Blindness and visual impairment in an urban West African population: the tema eye survey," Ophthalmology, vol. 119, no. 11, pp. 1744-1753, 2012.

[12] B. Wiafe, A. Quainoo, and P. Antwi, Ghana Blindness and Visual Impairment Study 2015, Ghana Health Service Operation Eyesight Universal, Accra, Ghana, 2015.

[13] R. R. Bourne, G. A. Stevens, and R. A. White, "Causes of vision loss worldwide, 1990-2010: a systematic analysis," The Lancet Global Health, vol. 1, no. 6, pp. e334-e339, 2013.

[14] S. Flaxman, R. Bourne, and S. Resnikoff, "Global causes of blindness and distance vision impairment 1990-2020: a systematic review and meta-analysis," The Lancet Global Health, vol. 5, no. 12, pp. 1221-1234, 2017.

[15] Y.-C. Liu, M. Wilkins, T. Kim, B. Malyugin, and J. S. Mehta, "Cataracts," The Lancet, vol. 390, no. 10094, pp. 600-612, 2017.

[16] M. Khairallah, R. Kahloun, R. Bourne et al., "Number of people blind or visually impaired by cataract worldwide and in world regions, 1990 to 2010," Investigative Opthalmology \& Visual Science, vol. 56, no. 11, pp. 6762-6769, 2015.

[17] J. H. Seland, J. R. Vingerling, C. A. Augood et al., "Visual impairment and quality of life in the older european population, the EUREYE study," Acta Ophthalmologica, vol. 89, no. 7, pp. 608-613, 2011.

[18] B. D. Nuertey, A. I. Alhassan, A. D. Nuertey et al., "Prevalence of obesity and overweight and its associated factors among registered pensioners in Ghana; a cross sectional studies," BMC Obesity, vol. 4, no. 1, p. 26, 2017.

[19] United Nations Population Fund Help Age International, Ageing in the Twenty-First Century: A Celebration and a Challenge, United Nations Population Fund Help Age New, New York, NY, USA, 2012.

[20] D. Rose, D. Pevalin, and K. O'Reilly, The National Statistics Socio-Economic Classification: Origins, Development and Use, Palgrave Macmillan, New York, NY, USA, 2005.

[21] E. Prokofyeva, A. Wegener, and E. Zrenner, "Cataract prevalence and prevention in Europe: a literature review," Acta Ophthalmologica, vol. 91, no. 5, pp. 395-405, 2013.

[22] R. Dandona and L. Dandona, "Socioeconomic status and blindness," British Journal of Ophthalmology, vol. 85, no. 12, 2001.

[23] A. Tafida, F. Kyari, M. M. Abdull et al., "Poverty and blindness in Nigeria: results from the national survey of blindness and visual impairment," Ophthalmic Epidemiology, vol. 22, no. 5, pp. 333-341, 2015.

[24] J. Ramke, A. B. Zwi, A. Palagyi, I. Blignault, and C. E. Gilbert, "Equity and blindness: closing evidence gaps to support universal eye health," Ophthalmic Epidemiology, vol. 22, no. 5, pp. 297-307, 2015.

[25] V. Kuuire, E. Bisung, and A Rishworth, "Health-seeking behaviour during times of illness: a study among adults in a resource poor setting in Ghana," Journal of Public Health, vol. 38, no. 4, pp. e545-e553, 2016.

[26] M. Yang, J. Zhang, S. Su et al., "Allelic interaction effects of DNA damage and repair genes on the predisposition to age- 
related cataract," PLoS One, vol. 13, no. 4, Article ID e0184478, 2018.

[27] C. Owsley, “Aging and vision,” Vision Research, vol. 51, no. 13, pp. 1610-1622, 2011.

[28] J. J. Wang, E. Rochtchina, A. G. Tan, R. G. Cumming, S. R. Leeder, and P. Mitchell, "Use of inhaled and oral corticosteroids and the long-term risk of cataract," Ophthalmology, vol. 116, no. 4, pp. 652-657, 2009.

[29] B. D. Nuertey, J. Addai, A. D. Nuertey, C. Kabutey, V. Adongo, and I. A. Mensah, "Prevalence and factors associated with self-reported pensioners in Ghana," Postgraduate Medical Journal of Ghana, vol. 8, no. 1, pp. 38-46, 2019.

[30] J. M. Tielsch, A. Sommer, J. Katz, H. Quigley, and S. Ezrine, "Socioeconomic status and visual impairment among urban Americans," Archives of Ophthalmology, vol. 109, no. 5, p. 637, 1991. 


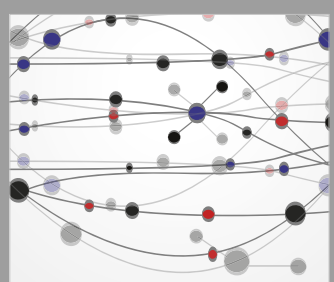

The Scientific World Journal
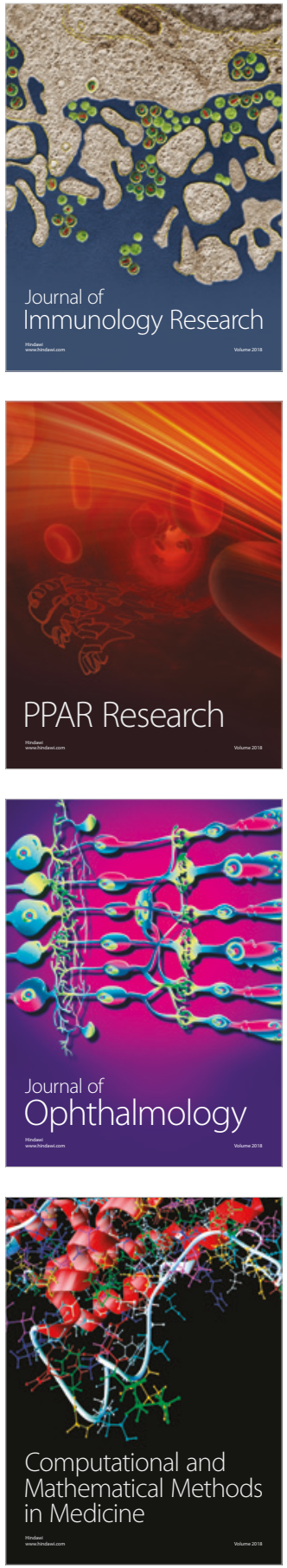

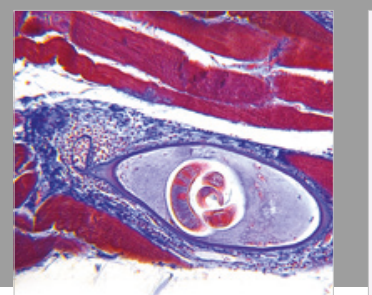

Gastroenterology Research and Practice

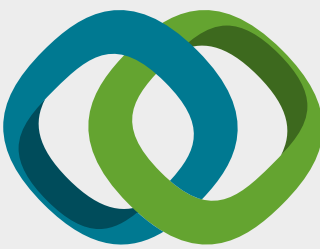

\section{Hindawi}

Submit your manuscripts at

www.hindawi.com
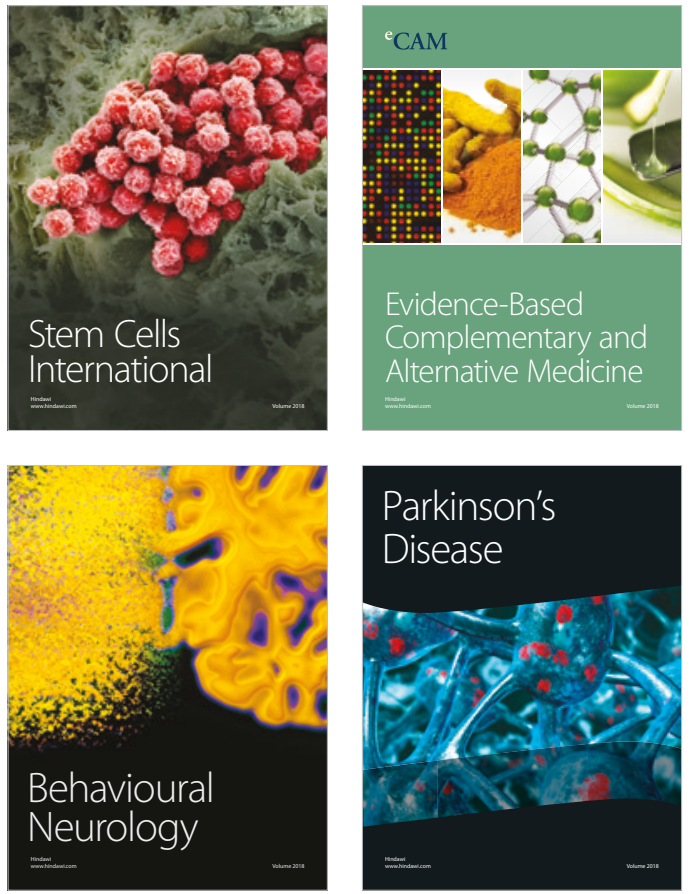

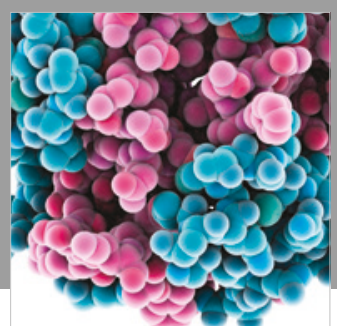

ournal of

Diabetes Research

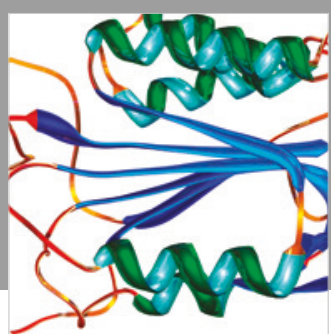

Disease Markers
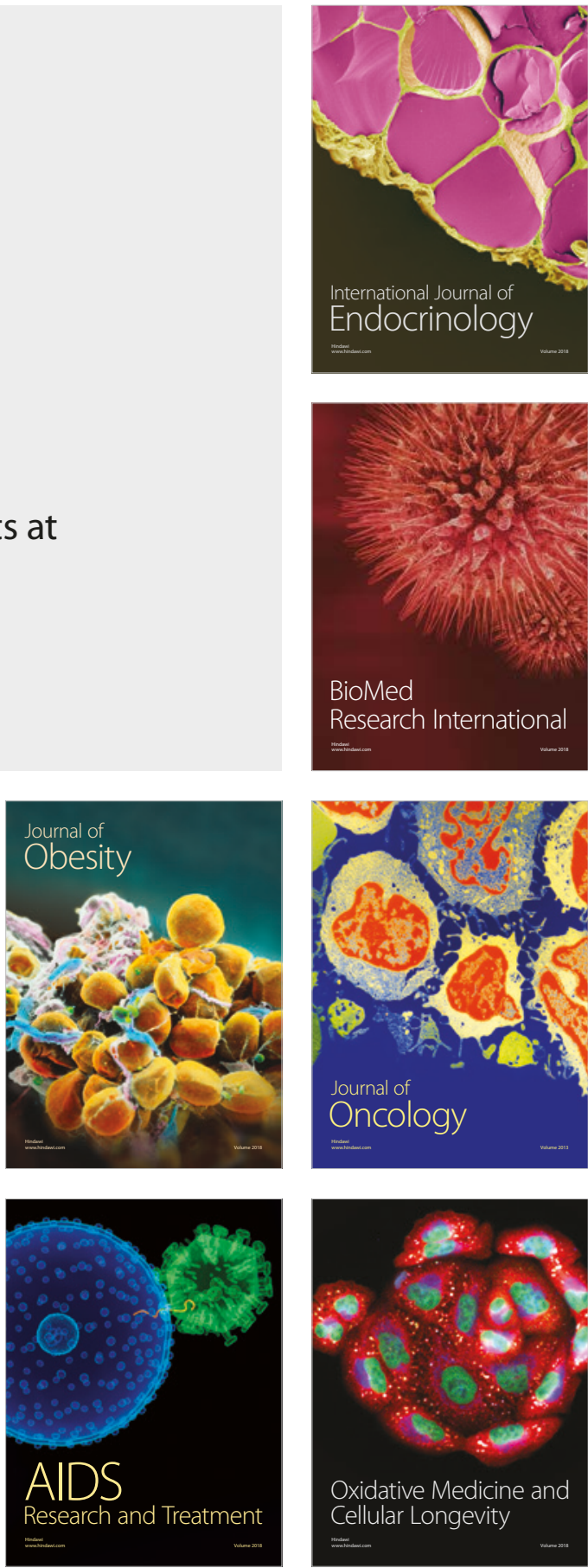